\title{
TOWARDS AN EUROPEAN CERTIFICATION OF COMPUTER SCIENCE UNIVERSITY CURRICULA
}

\author{
Agostino Cortesi \\ Università Ca' Foscari di Venezia \\ cortesi@unive.it
}

\author{
Enrico Nardelli \\ Università di Roma "Tor Vergata" \\ nardelli@mat.uniroma2.it
}

\begin{abstract}
The paper describes the certification mark promoted by the Italian Association of Computer Science University Professors (GRIN) for undergraduate and graduate degree programs in Computer Science. The certification process yields a system of comparable and transparent curricula that enables the comparison of different sites and supports student mobility across different Universities. It can be seen as a first step towards a European Certification of Computer Science University Curricula.
\end{abstract}

\section{Keywords}

Quality assurance, Transparency of curricula.

\section{INTRODUCTION}

Computer Science university degree programs are required both to provide students with a solid scientific and technological background, and to cover as much as possible the wide spectrum of disciplines exploiting the computer science methodology.

The autonomy that has been granted to universities in the specification of their curricula forces the faculties to qualify their products with respect to the plethora of courses that are offered in the educational market. Students and families often get confused by radio and TV commercials. Also when focusing just on curricula offered by the university system, it is very difficult to evaluate the values of curricula that look very similar. The same holds for enterprises and recruitment agencies, having difficulties to classify the different universities with respect to the quality of each degree program as the content and the structure of the whole university system has deeply changed in the last decade.

In this context, each university delivering a degree program in Computer Science (CS) should be fair enough to guarantee that their curricula cover the basic spectrum of scientific knowledge in CS, and that courses are given by qualified professors.

Unfortunately, the conditions above are not always satisfied. For instance, there are university degree programs in CS where not even one faculty member has a PhD neither in Computer Science nor in Computer Engineering.

GRIN, the Italian Association of Computer Science University Professors (http://www.di.unipi.it/grin) promoted a common effort involving almost all of the Italian universities towards the elicitation of the "product qualities" of undergraduate degree programs in CS, and characterized the constraints to be fulfilled in order to obtain the GRIN quality certification. Rules and results of this certification process are made public, in order to provide families and enterprises with information to make the right choice. There is no other similar initiative in the Italian academic context, and as far as we know, in Europe only the Chemistry Eurobachelor has similar purposes. In order to manage this certification 
process, a web site is maintained by Università di Roma "Tor Vergata". This project is supported by the Italian Council of University Deans (CRUI).

The result of the 2004, '05 and '06 certification process are available at the URL http://grin.informatica.uniroma2.it/ by connecting as generic user. In 2006, more than 40 undergraduate degree programs in CS have been granted the GRIN certification mark (out of 54).

\section{Certification Requirements}

The GRIN Association decided to adopt the following criteria in order to avoid the need for heavy organizational duties: the quantity of data to be treated should be quite limited; data should be easy to get and to check; data should be already available at each site, as part of the usual public information provided to potential students.

The GRIN quality certification is based on the verification of the fulfilment of a set of constraints on the programs.

The general guidelines to define the certification rules are as follows:

- The percentage of courses in CS in the degree program has to be relevant.

- The main areas of CS should be properly covered

- The degree program should not too much focussed on a single area.

Two certification levels were designed, the first one aimed at undergraduate degree programs (certificazione base), the second one for graduate degree programs or for very focussed undergraduate programs (certificazione avanzata).

Observe that also graduate programs having an interdisciplinary character might be granted a first level certification.

Taking inspiration from the ACM-IEEE classification, a list of 11 main CS areas was identified, as depicted in Fig.1, and a detailed list of subtopics were associated to each of them.
A. Foundations
B. Algorithms
C. Programming
D. Computer Languages
E. Computer Architectures
F. Operating Systems
G. Data Bases
H. Network Computing
I. Software Engineering
L. Human Computer Interaction - Graphics - Multimedia
M. Knowledge Representation

Fig.1: Main CS Areas

The certification rules are defined in terms of credits (cfu, where one cfu corresponds to 25 hours of learning activities, including lectures, training, and individual study for the average student). 
In order to be eligible for the GRIN quality certification mark, each University degree program in CS must satisfy the following constraints:

1. At least 78 cfu must be assigned to learning activities in CS or in Computer Engineering.

2. At least $60 \mathrm{cfu}$ (out of the 78 above) must be assigned to learning activities in the 11 areas listed in Fig. 1

3. At least 7 areas (out of the 11 listed in Fig.1) must be covered by at least 6 cfu.

It is easy to verify that these rules strictly correspond to the three criteria presented above. The first rule guarantees that more than $1 / 3$ of the program is specifically dedicated to CS topics; the rest of the credits should cover mathematical and physical foundations, more specialized topics, or complementary aspects (e.g., legal, economical, and ethical issues). The second rule guarantees a good coverage of the main areas of CS; observe that credits assigned to the same area can be spread among different courses. Finally, the third rule prevents from degree programs whose scope is too narrow: at least half of the 11 areas must be properly covered, say by at least 48 hours of lectures.

We are aware that this approach only provides benchmarks for the scope of curriculum and that other issues need to be considered in the future to get to a complete accreditation process.

\section{THE SUPPORTING WEB APPLICATION}

Each year, the chair of each CS degree program may apply for the GRIN quality certification by inserting in the certification web site the data concerning the activated curricula, and the syllabus of each course taught. For each course, the following information has to be provided: total number of credits, number of credits labelled as "computer science", and corresponding area (see Fig.1). A brief description of the contents of each credit (ects) in the 11 areas has to be inserted as well, according to the sub-areas depicted in Fig.2. Observe that this data results in a system of comparable and transparent curricula that allows both the comparison of different curricula and student mobility. Three screenshots of the systems are depicted in Fig. 3 to Fig. 6.

\section{THE CERTIFICATION AUTHORITY}

The quality certification is issued by AICA, a certification authority that grants other CS certification marks like ECDL and EUCIP. It is important to notice that all the data about the certified courses are made public in the web: they offer the reader a complete and synoptic picture of the main academic degree programs in Computer Science (also of the universities that do not fulfil the certification requirements). 


\section{Conclusions}

The GRIN quality certification mark of university degree programs in Computer Science might be the basis for discussion about a European certification of Computer Science curricula, as it yields a system of comparable and transparent curricula that allows the comparison of what is offered by the different institutions, and most of all it supports student mobility in an European context. As a future work, we also aim at comparing our approach with the UK benchmarks (HTTP://WWW.QAA.AC.UK).

\section{REFERENCES}

[1] ACM-IEEE Computing Curricula 2001 Joint Task Force on Computing Curricula. http://www.computer.org/education/cc2001/

[2] Cortesi A., and Nardelli E., The Quality Certification Mark for Italian University Degree Programs in Computer Science. Proc. 8th IFIP World Conference on Computers in Education, Cape Town, South Africa, July 2005, ISBN 1-920-01711-9 


\begin{tabular}{|c|c|}
\hline $\begin{array}{l}\text { A. FOUNDATIONS } \\
* \text { ALF - Automata and Formal Languages } \\
* \text { CAL -Computability } \\
* \text { COM - Complexity } \\
* \text { SLP - Semantics of Programming Languages } \\
\text { TIC - Information Theory } \\
\text { L - Logics } \\
\text { SD - Dynamical Systems } \\
\text { V - Other Topics }\end{array}$ & $\begin{array}{l}\text { B. ALGORITHMS } \\
\text { * SDF - Fundamentals of Data Structures } \\
\text { * TAPA - Basic Techniques for Algorithm Analysis and Design } \\
\text { * A - Fundamentals of Algorithms } \\
\text { * ASC - Algorithms for Combinatorial Structures } \\
\text { TAA - Advanced Algorithmic Techniques } \\
\text { SDA - Advanced Data Structures } \\
\text { AD -Distributed Algorithms } \\
\text { AP - Parallel Algorithms } \\
\text { AN - Numerical Algorithms } \\
\text { V - Other Topics }\end{array}$ \\
\hline $\begin{array}{l}\text { C. PROGRAMMING } \\
\text { * PSA - Problem Solving and Algorithms } \\
\text { * SS - Syntax and Semantics } \\
\text { * CB - Fundamentals of Programming Structures } \\
\text { * P - Procedures and Functions } \\
\text { * R - Recursion } \\
\text { * SDTD- Basic Data Structures and Abstract Data Types } \\
\text { * SCP - Program Development and Correctness } \\
\text { * POO - Object Oriented Programming } \\
\text { PP - Programming Paradigms } \\
\text { PPCC - Concurrent Programming } \\
\text { V - Other Topics }\end{array}$ & $\begin{array}{l}\text { D. LANGUAGES } \\
\text { * LF - Formal Languages } \\
* \text { S - Semantics } \\
* \text { MATR - Abstract Machines and Techniques for Implementing } \\
\text { Programming Languages } \\
\text { * TTCI - Compilers and Intepreters } \\
\text { PLN - Programming Languages Paradigms } \\
\text { ALC - Linguistic Abstraction and Compositionality } \\
\text { MP - Programming Methodologies } \\
\text { TAV - Analysis and Verification Techniques } \\
\text { V- Other Topics }\end{array}$ \\
\hline $\begin{array}{l}\text { E. ARCHITCTURES } \\
\text { * CCS - Combinatorial and Sequential Circuits } \\
\text { * AC - Computer Arithmetics } \\
\text { * LIS - Instruction Set Level } \\
\text { * LMP - Microprogramming Level } \\
\text { * ASS - Assembly Language } \\
\text { GM - Memory Management } \\
\text { GIO - Input/Output Management } \\
\text { VMP - Performance Evaluation and Optimization } \\
\text { AA - Advanced Architecture } \\
\text { V - Other Topics }\end{array}$ & $\begin{array}{l}\text { F. OPERATING SYSTEMS } \\
\text { * SC - Structure and Component of an Operating System } \\
\text { * GSP - Process Management and Synchronization } \\
\text { * GM - Memory Management } \\
\text { * FS - File System } \\
\text { * AMM - System Administration } \\
\text { GP - Peripheral Management } \\
\text { GCA - Access Control and Management } \\
\text { PS - System Programming } \\
\text { MA - Models and Architectures of Operating Systems } \\
\text { SAA - Operating Systems for Advanced Computing Architectures } \\
\text { V - Other Topics }\end{array}$ \\
\hline $\begin{array}{l}\text { G. DATA BASES } \\
\text { * ML - Logical Models } \\
\text { * PC - Conceptual Design } \\
\text { * PL - Logical Design } \\
\text { * LI - Query Languages } \\
\text { * DBMS - Data Base Management Systems } \\
\text { LP - Data Base Programming Languages } \\
\text { NBD - Data Base Normalization } \\
\text { OFGI - Physical Organization and Query Processing } \\
\text { TCR - Transactions, Concurrency, and Recovery } \\
\text { BDA - Advanced Data Bases } \\
\text { V - Other Topics }\end{array}$ & $\begin{array}{l}\text { H. NETWORK COMPUTING } \\
\text { * FCD - Fundamentals of Distributed Computation } \\
\text { * ARTC - Computer Network Architectures } \\
\text { * PT - Protocols } \\
\text { * SR - Network Security } \\
\text { * MIR - Models for Interaction in Networks } \\
\text { SRM - Network Operating Systems and Network Programming Middleware } \\
\text { PASR - Application and Service Programming } \\
\text { GRC - Network Management } \\
\text { DR - Network Devices } \\
\text { V - Other Topics }\end{array}$ \\
\hline $\begin{array}{l}\text { I. SOFTWARE ENGINEERING } \\
\text { * PSS - Software Development Processes } \\
\text { * LMS - Software Modeling Languages } \\
\text { * AR - Requirement Analysis } \\
\text { * ASW - Software Architecture } \\
\text { * PSC - Software Design and Coding } \\
\text { * TVV - Testing, Verification, and Validation } \\
\text { AS - Development Environment } \\
\text { MES - Software Maintenance and Evolution } \\
\text { EPGS - Economics of Software Production and Management } \\
\text { MSQ - Software Measurement and Quality } \\
\text { EPG - Ethical, Professional and Legal Issues } \\
\text { V Other Topics }\end{array}$ & $\begin{array}{l}\text { L. HC INTERACTION, GRAPHICS AND MULTIMEDIA } \\
\text { * MMPI - Models and Methods for Interaction Design } \\
\text { * PMTV - Principles, Methods and Techniques for Interface Evalution } \\
\text { * IMW - Hypertexts, Multimedia and WWW } \\
\text { TMI - Human-Computer Interaction: Theories and Models } \\
\text { PIRV - Interaction Paradigms and Virtual Reality } \\
\text { SIAS - Interaction Support System and Development Environment } \\
\text { MG - Geometrical Modelling } \\
\text { RV - Rendering and Visualization } \\
\text { ESM - Multimedia Signal Processing } \\
\text { V - Other Topics }\end{array}$ \\
\hline $\begin{array}{l}\text { M. KNOWLEDGE REPRESENTATION } \\
* \text { RP - Problem Representation } \\
\text { * SBC - Knowledge-Based Systems } \\
\text { * LPD - Logics and Declarative Programming } \\
\text { ARC - Knowledge Acquisition and Representation } \\
\text { AI - Intelligent Agents } \\
\text { RA - Automated Reasoning } \\
\text { AASC - Automated Learning and Knowledge Discovery } \\
\text { BC - Knowledge Bases } \\
\text { AIA - Artificial Intelligence Application } \\
\text { V - Other Topics }\end{array}$ & \\
\hline
\end{tabular}

Fig. 2: The GRIN classification of Computer Science Education Areas 


\section{Sistema di certificazione \\ della qualità dei contenuti delle lauree \\ in Informatica nelle facoltà \\ di Scienze MM.FF.NN.}

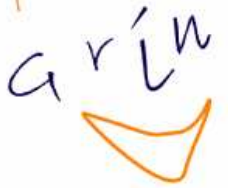

Perche' un marchio di qualità?

Di che si tratta?

\section{Benvenuto}

Entra nel sistema per l'anno $\underline{2006}$

Consulta i dati per l'anno $\underline{2005}$ oppure per l'anno $\underline{2004}$

Fig. 3: The home page of the Certification Site

Eile Modifica Yisualizza Preferiti Ștrumenti ?

Corsi di laurea

\begin{tabular}{|c|c|c|c|}
\hline Corsi di laurea di primo livello & Università di & Responsabile & Certificazione \\
\hline Informatica - Percorso A: Sistemi basati su conoscenza & Bari & $\begin{array}{l}\text { Maria Francesca } \\
\text { Costabile }\end{array}$ & AVANZATA \\
\hline Informatica - Percorso B: Progettazione del software & Bari & $\begin{array}{l}\text { Maria Francesca } \\
\text { Costabile }\end{array}$ & AVANZATA \\
\hline Informatica - Percorso C: Sistemi di elaborazione intelligenti & Bari & $\begin{array}{l}\text { Maria Francesca } \\
\text { Costabile }\end{array}$ & AVANZATA \\
\hline Informatica e Comunicazione Digitale - Indirizzo: Sistemi di e-topics & Bari & $\frac{\text { Vito Leonardo }}{\text { Plantamura }}$ & AVANZATA \\
\hline Informatica e Comunicazione Digitale - Indirizzo: Sistemi Software Avanzati & Bari & $\frac{\text { Vito Leonardo }}{\text { Plantamura }}$ & AVANZATA \\
\hline Informatica e Tecnologie per la Produzione del Software & Bari & Giuseppe Visaggio & AVANZATA \\
\hline Informatica & Bologna & Maurizio Gabbrielli & BASE \\
\hline Scienze dell'Informazione & Bologna - sede di Cesena & Marilena Barnabei & BASE \\
\hline Informatica - Curriculum Sistemi & Ca' Foscari di Venezia & Marcello Pelillo & BASE \\
\hline Informatica - Curriculum Applicazioni & Ca' Foscari di Venezia & Marcello Pelillo & BASE \\
\hline Informatica-Curriculum Gestionale & Ca' Foscari di Venezia & Marcello Pelillo & BASE \\
\hline Informatica & Cagliari & G. Michele Pinna & BASE \\
\hline Informatica - Indirizzo Tecnologie Informatiche & Camerino & Flavio Corradini & BASE \\
\hline Informatica - Indirizzo Informatica e Management & Camerino & Flavio Corradini & BASE \\
\hline Informatica & Catania & Giovanni Gallo & AVANZATA \\
\hline Laurea in Informatica & Federico II di Napoli & Adriano Peron & BASE \\
\hline$\underline{\text { Informatica }}$ & Firenze & Elena Barcucci & BASE \\
\hline Informatica - Curriculum Progettazione Software & Genova & Enrico Puppo & BASE \\
\hline
\end{tabular}

Fig. 4: The (partial) list of 2006 certified curricula 
Dati del corso di laurea: Informatica - Curriculum Sistemi

Informazioni generali

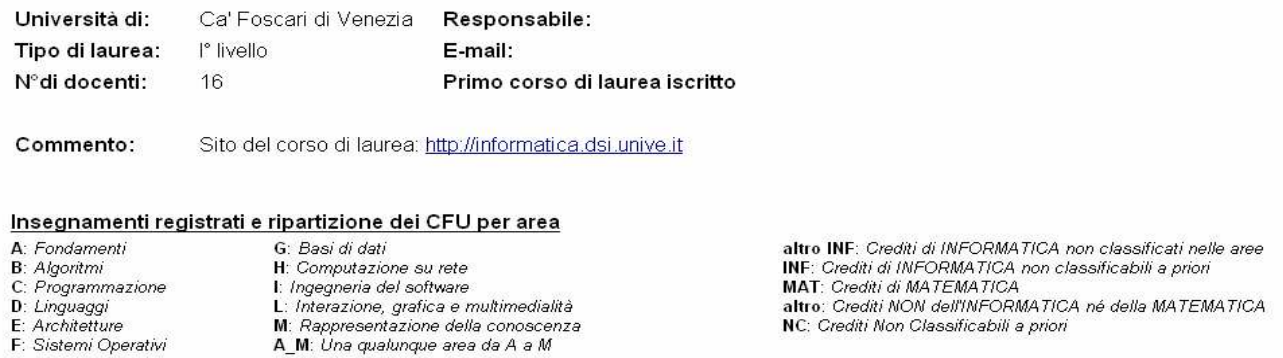

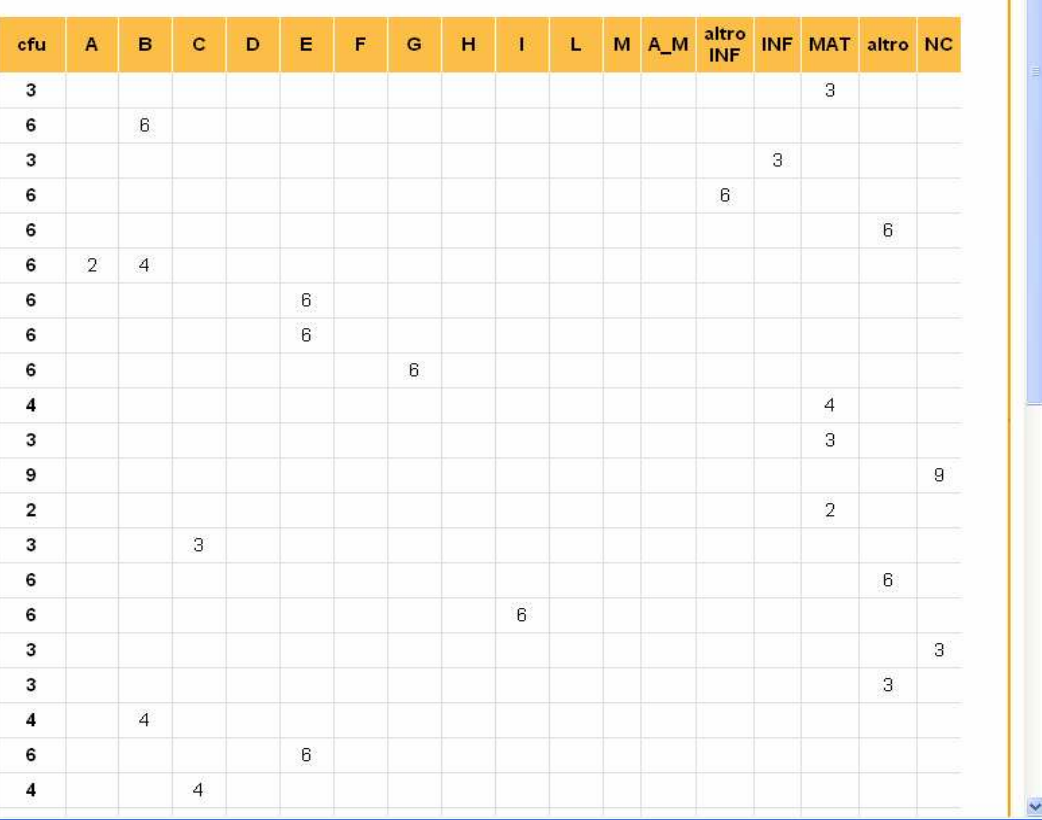

Fig. 5: The description of a CS curriculum. Each course is classified within the CS areas (see Fig. 1), and it may cover more than one of them (for instance, the $6 \mathrm{cfu}$ of "Analisi e Progetto di Algoritmi" are classified in the "Foundation" and in the "Algorithms" areas). 
- Corso di laurea: Informatica - Curriculum Sistemi

- Università di Ca' Foscari di Venezia

- Tipo di laurea: ${ }^{\circ}$ livello

- 6 CFU cosi ripartiti nelle aree

$6 \mathrm{cfu}$ in B - Algoritmi

- 8 ore di didattica frontale per ogni CFU

B - Algoritmi

- 'TAPA - Tecniche fondamentali di Analisi e Progetto di Algoritmi

TAPA - Tecniche fondamentali di Analisi e Progetto di Algoritmi
Introduzione agli algoritmi e alla loro complessit?. Classi di complessit? I| metodo divide et impera. Ricorrenze e loro soluzioni

Introduzione agli algoritmi e alla loro com

*SDF - Strutture di Dati Fondamentali
Strutture Dati Elementari: Liste, Pile, Code, Alberi Binari e Alberi Posizionali

*SDF - Strutture di Dati Fondamentali

*SDF - Strutture di Dati Fondamentali
Propriet? degli alberi binari completi. La struttura dati heap. Heapify e costruzione di uno heap. La struttura dati coda con priorit

Propriet? degli alberi binari co

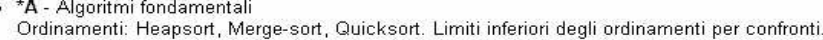

- * A - Algoritmi fondamentali

Alberi Binari di Ricerca: definizione, ricerca, inserimenti e rimozioni. Alberi Bilanciati: alberi Rossi e Neri, alberi AVL, alberi 2-3, B-alberi.

SDA - Strutture di Dati Avanzate

SDA - Strutture di Dati Avanzate
Grafi: definizione, rappresentazione, algoritmi di visita

Fig. 6: The syllabus of a course. In the example, course on Algorithm Design is described. The content of each credit unit (corresponding to 8 hours in class) is described in terms of sub-area labels (see Fig.2), with additional specifications. 